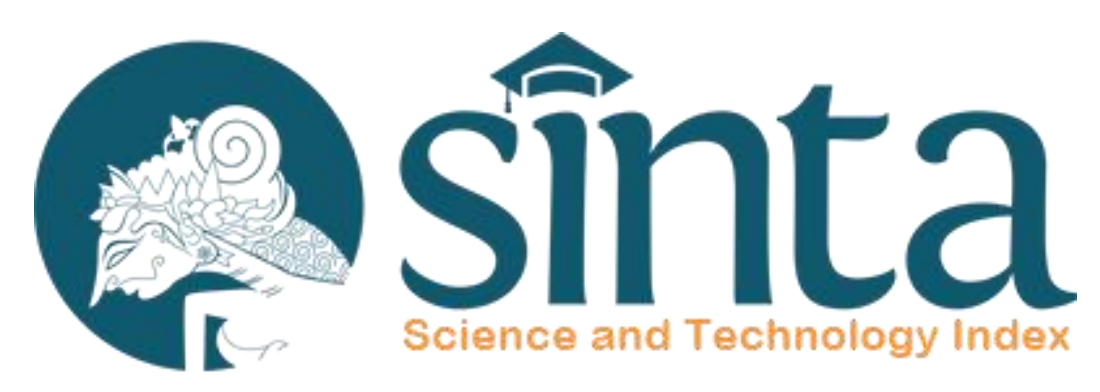

\title{
Science and Technology Index (SINTA) Verificator
}

\section{Leon Andretti Abdillah}

\author{
Editor Thomson Indexed Conferences (iCLICK) \\ Reviewer Scopus Indexed Journals (AJIS, EJEL, IJASEIT, IJCCC, KSII T Internet Info) \\ Reviewer Scopus Indexed Conferences (CITSM, ICAITI, ICIC) \\ Reviewer Accredited Journals (CommIT, IJAIN, JSINBIS) \\ Reviewer DOAJ Indexed Journals (ComTech, RESTI) \\ Secretary Intellectual Property Right \\ Advisor Mendeley \\ Verificator SINTA
}




\section{SINTA}

- Pelatihan SINTA Verificator, 26-27/03/2018

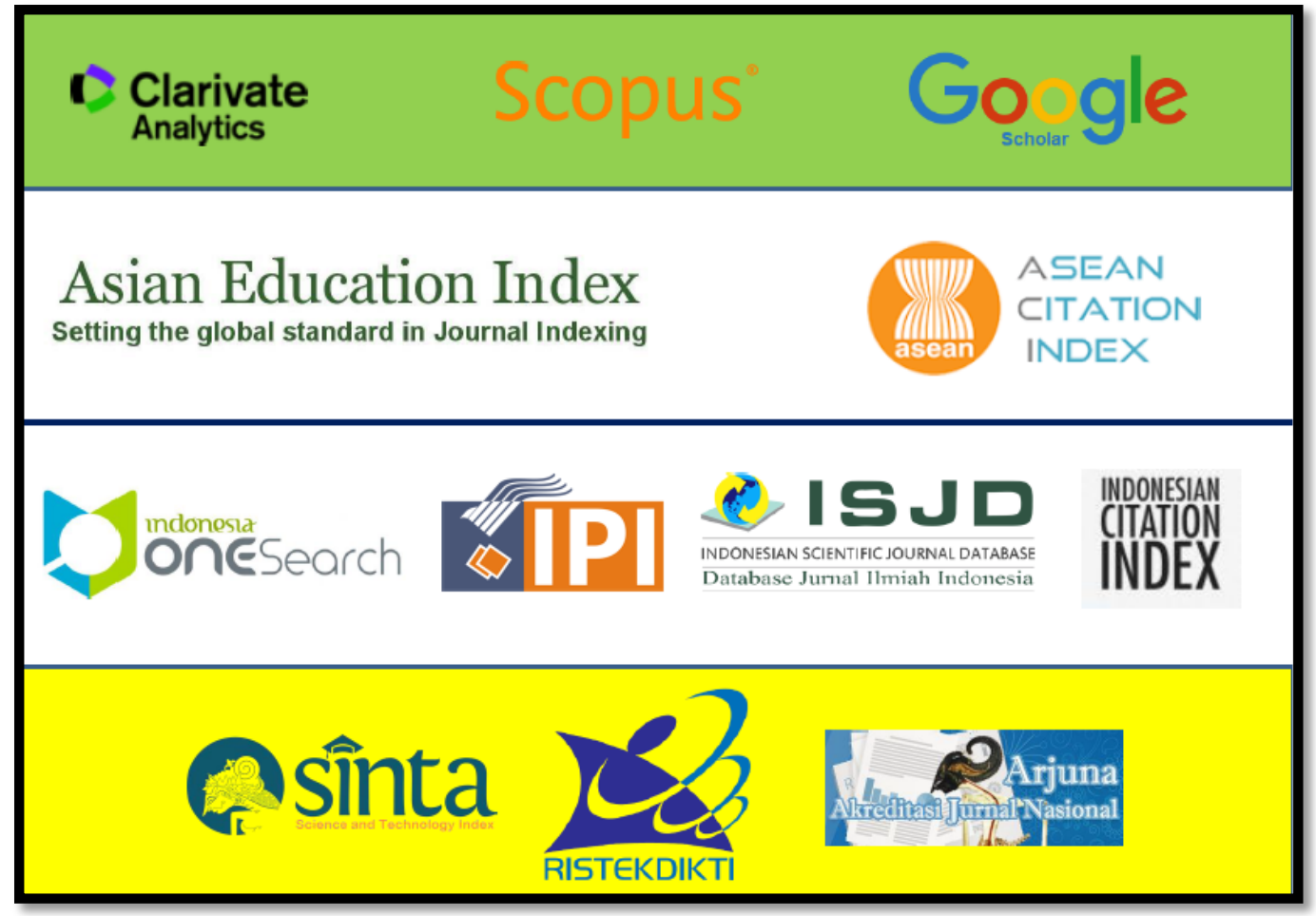

- $\quad$ SINTA $\rightarrow$ Pusat Indeks, Sitasi dan Kepakaran Terbesar di Indonesia 


\section{SINTA Statistik}

- Verified Authors $=86,481$ Authors (20180326)

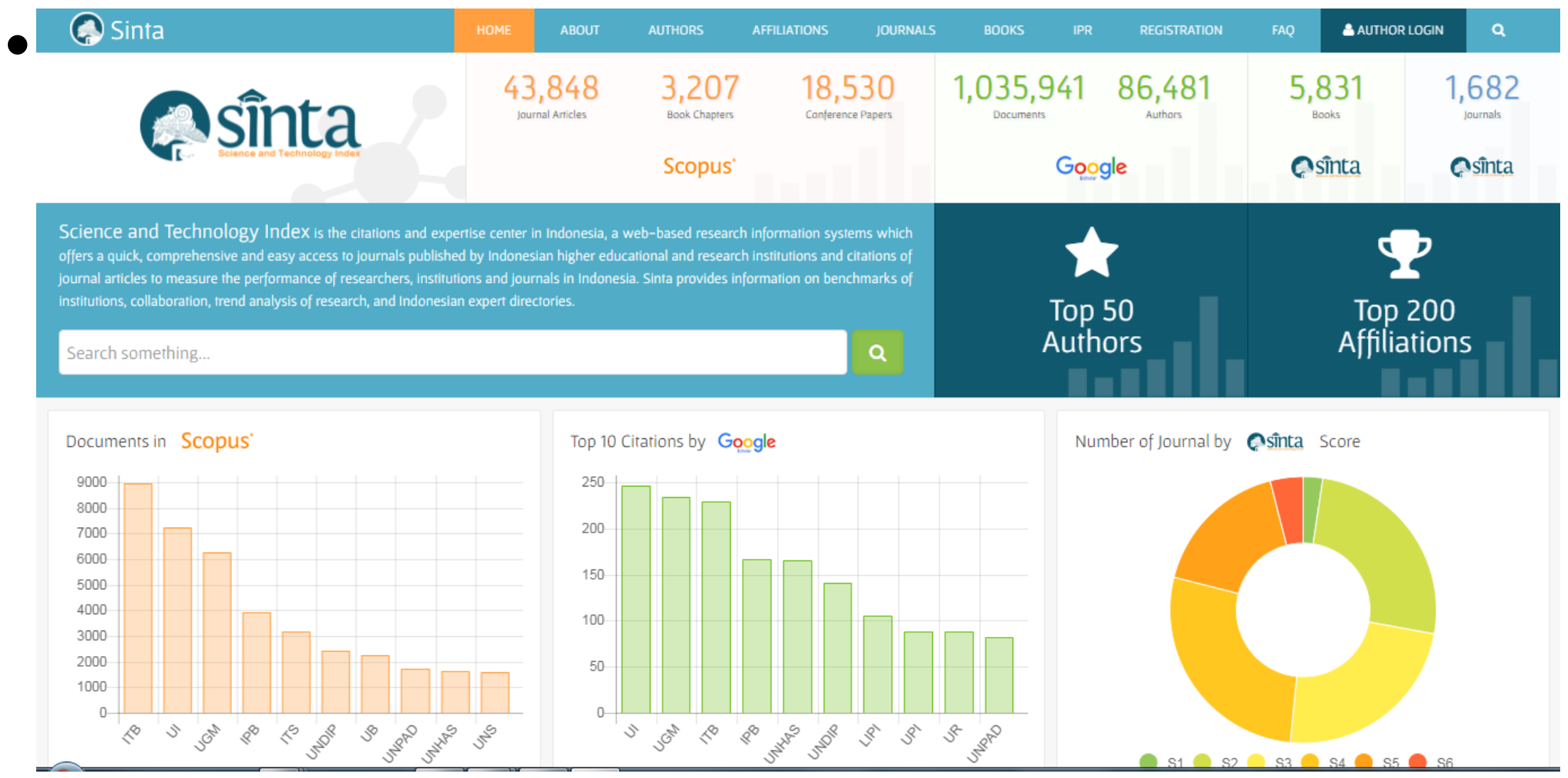


- Rekap Nasional Semester 2017/2018 Genap $\rightarrow$ https://forlap.ristekdikti.go.id/

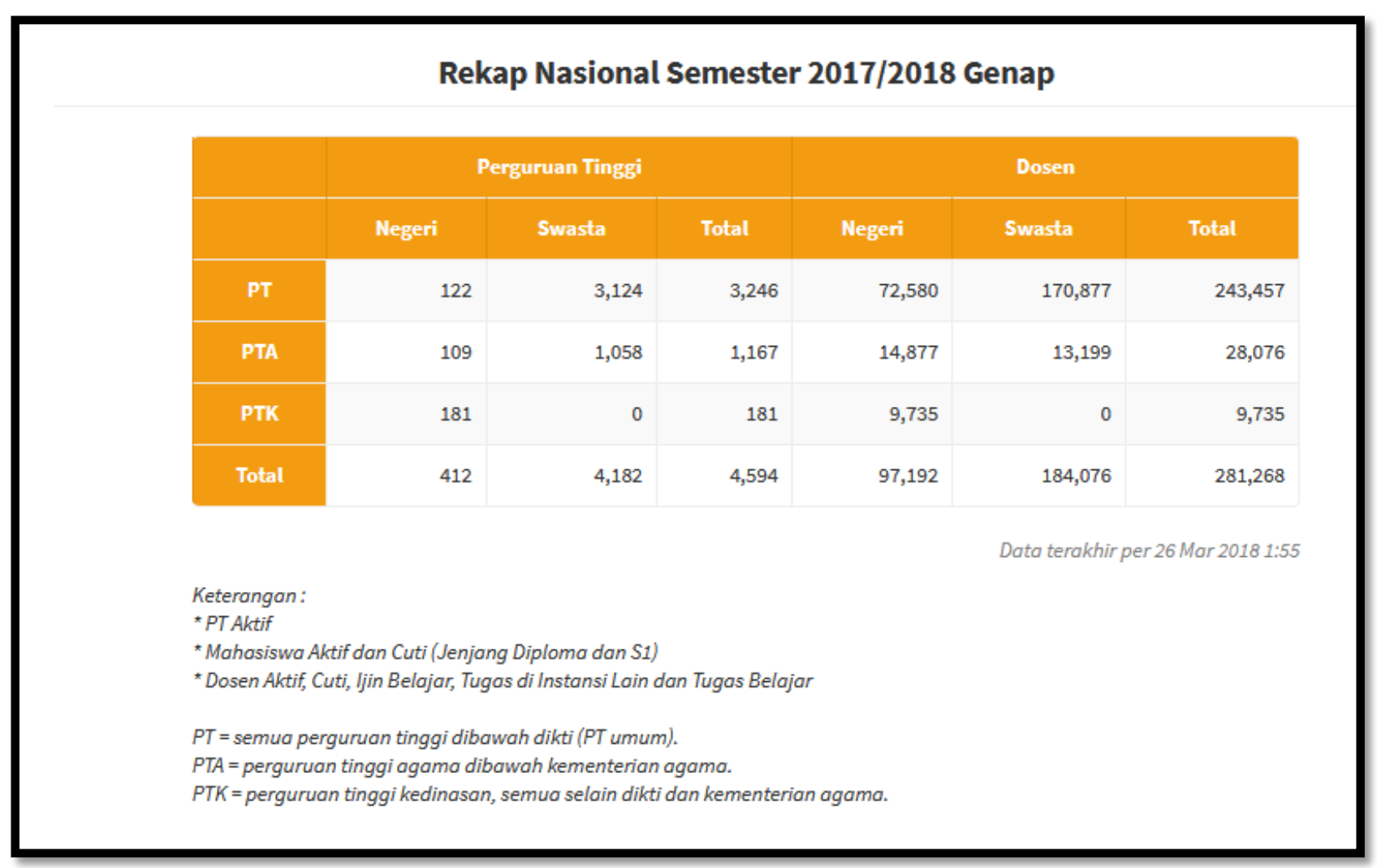

\begin{tabular}{|l|}
\hline Total \\
Dosen $=$ \\
281,268 \\
\hline
\end{tabular}

Verified Authors $=$ 86,481

UnVerified Authors $=$ ??? 


\section{Data SINTA Authors Per 20180326}

- Total Dosen

- Verified Authors

- Not Verified Authors yet $=194,747$ Authors

- Total Verifier saat ini
$=281,268$ Authors

$=86,481$ Authors

$=15$ Verifiers

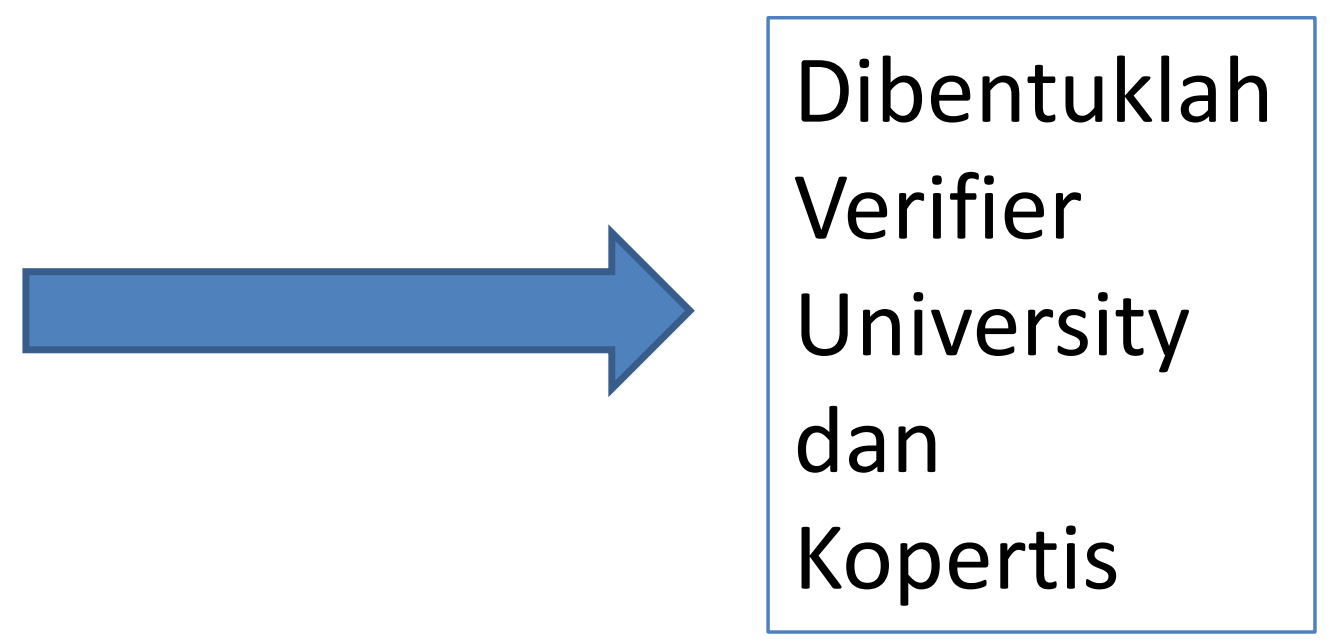




\section{Tahapan Verifikasi SINTA}

- Tahapan verifikasi SINTA

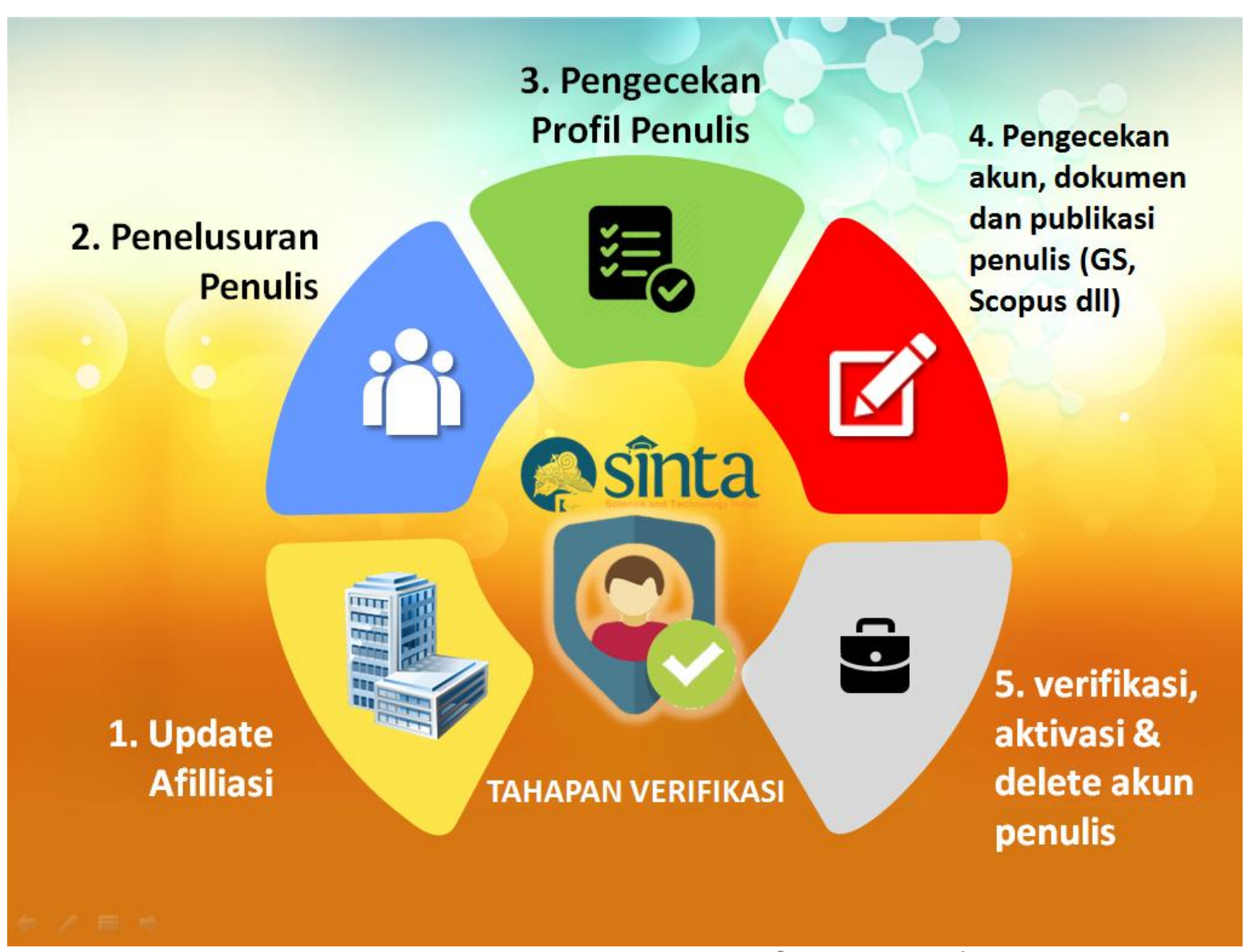




\section{SINTA University Verificator}

- SINTA University Verificator untuk Universitas Bina Darma 


\section{Update Afilliasi}

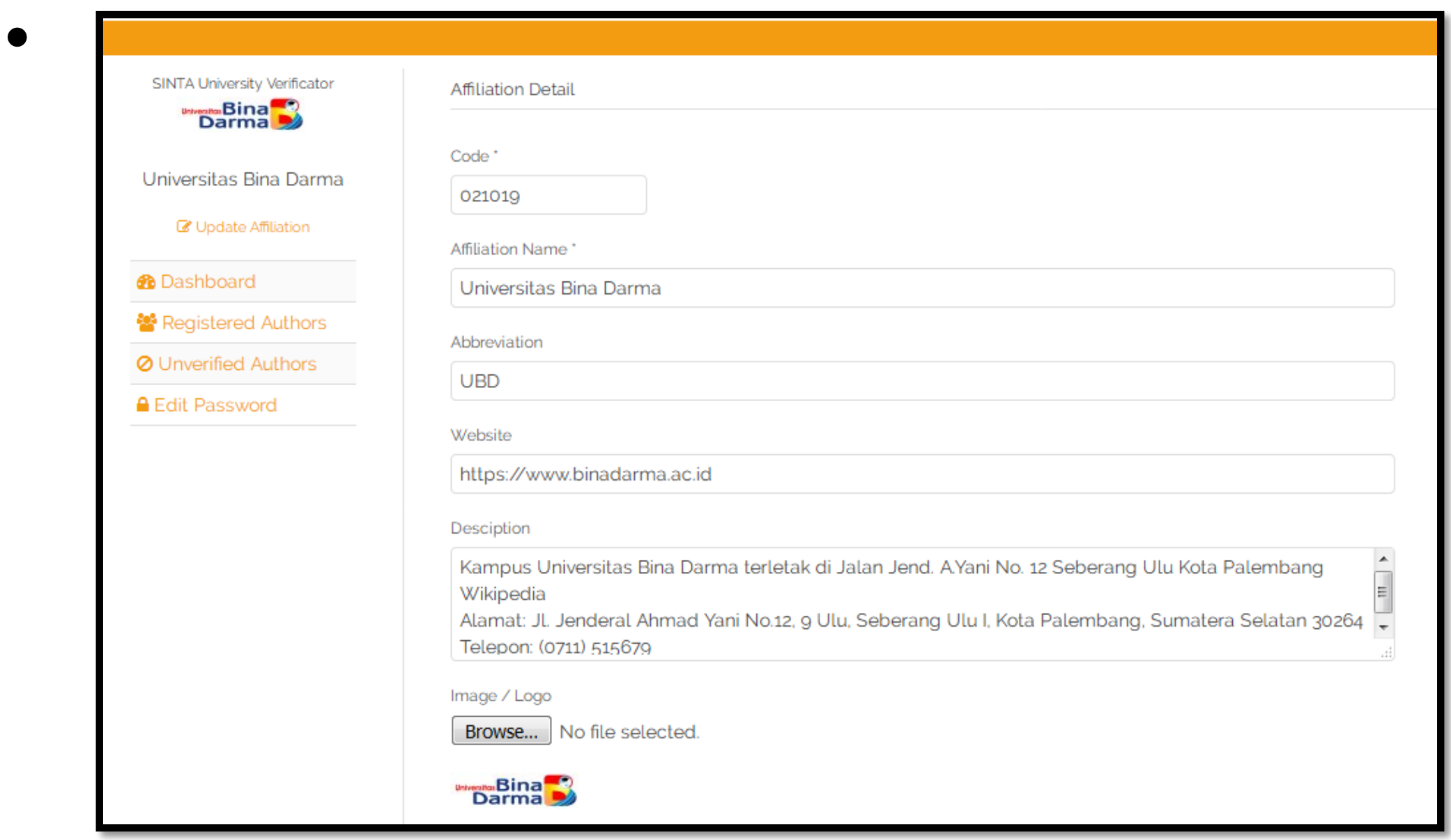




\section{UBD Authors in SINTA}

- Per 20180326, UBD Authors; 123 verified; 1 unverified

Cisinta

\begin{tabular}{|c|c|}
\hline SINTA Unive & Find Author \\
\hline Da & NIDN $=$ search... \\
\hline $\begin{array}{c}\text { Universitas Bina Darma } \\
\qquad \mathbb{Q} \text { Update Afflistion }\end{array}$ & Registered Authors \\
\hline Dashboard & \\
\hline Hegistered Authors & 1 \\
\hline Q Unverified Authors & \\
\hline
\end{tabular}

Edit Password

\section{3}

124 Activated Authors

O Not Activated Authors 


\section{Unverified Authors}

- UBD = 1 author

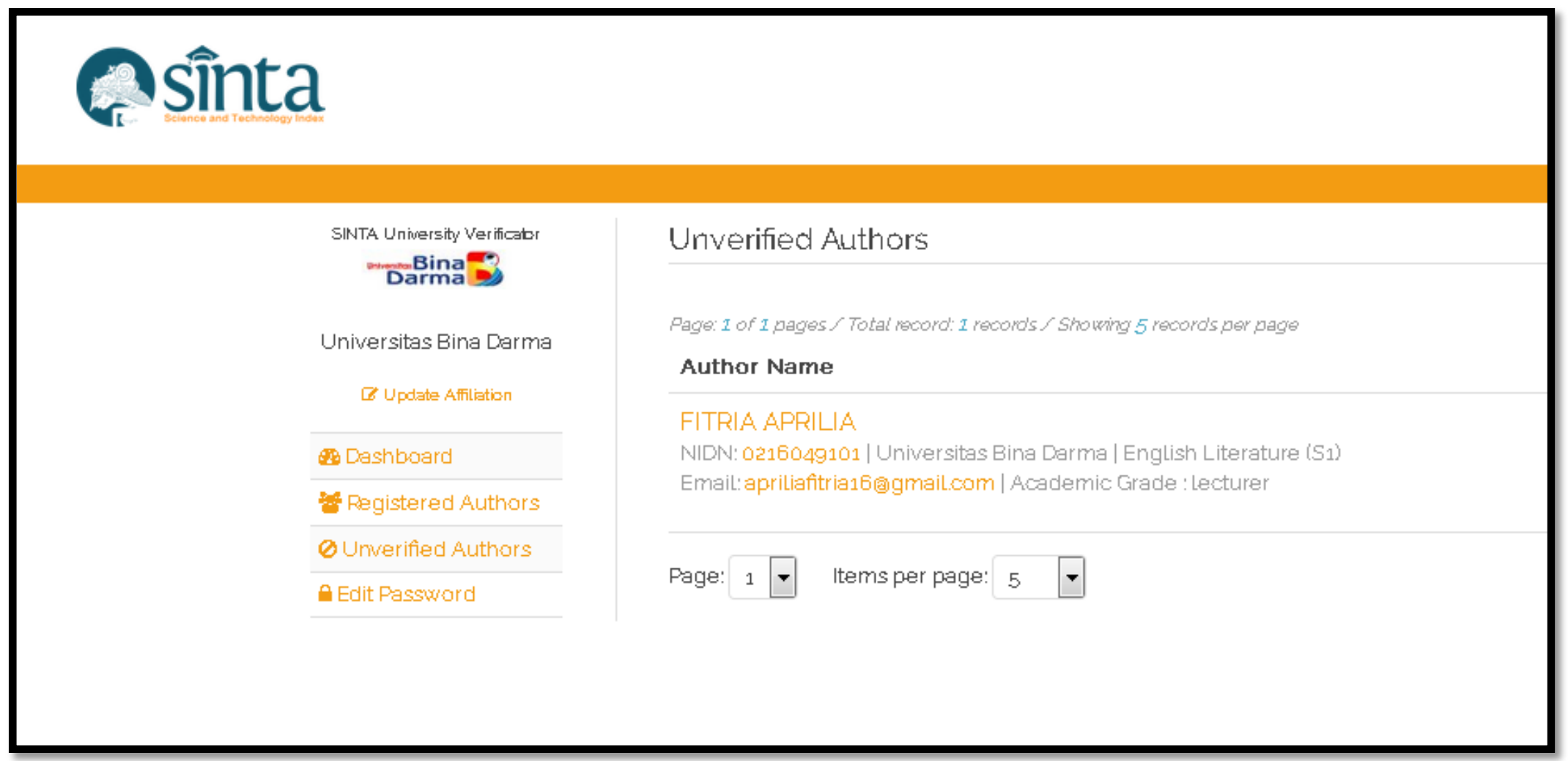




\section{Penelusuran Penulis}

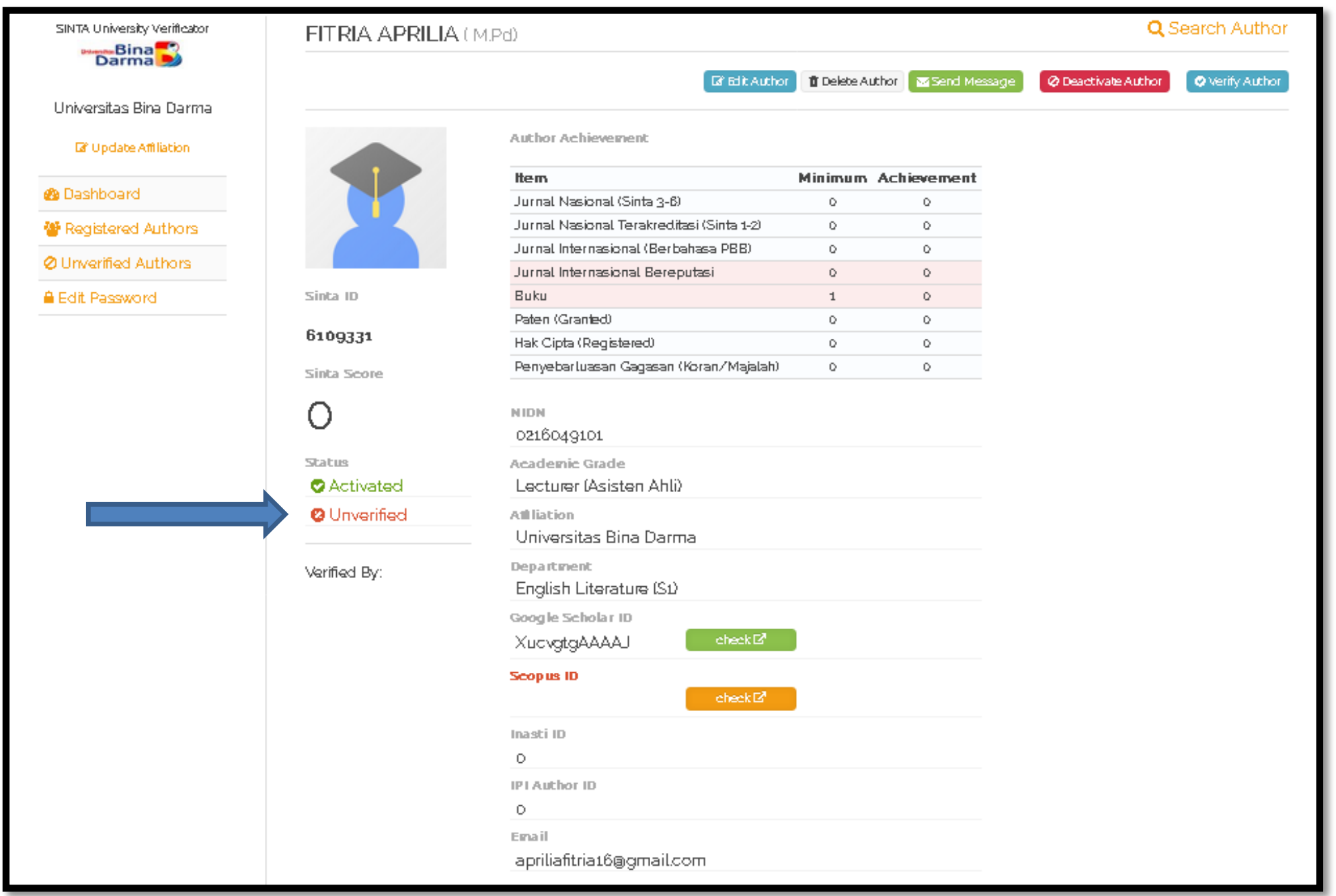




\section{Pengecekan Profil Penulis}

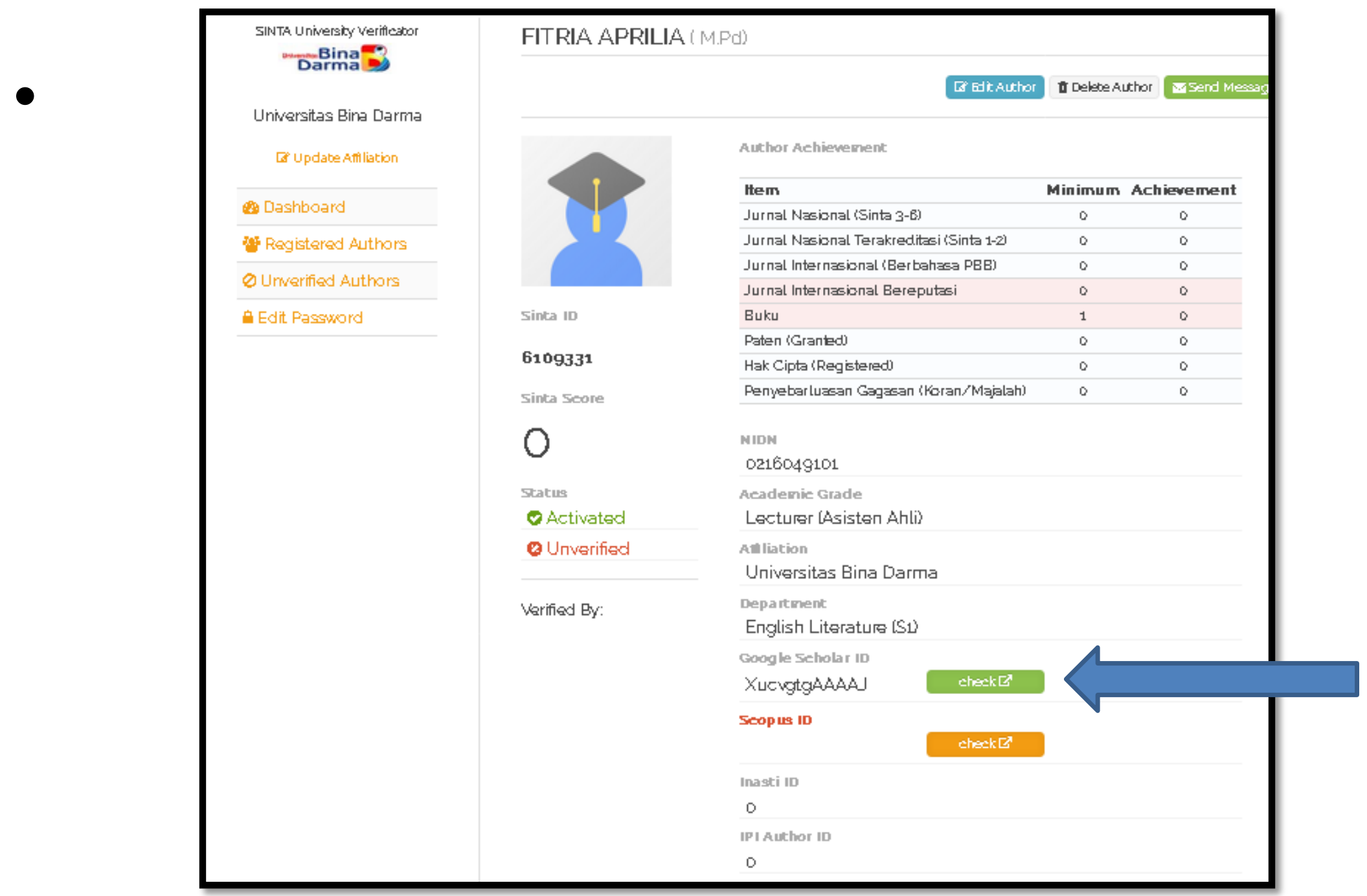


4. Pengecekan Akun, Dokumen dan Publikasi Penulis (GS, Scopus, dII)

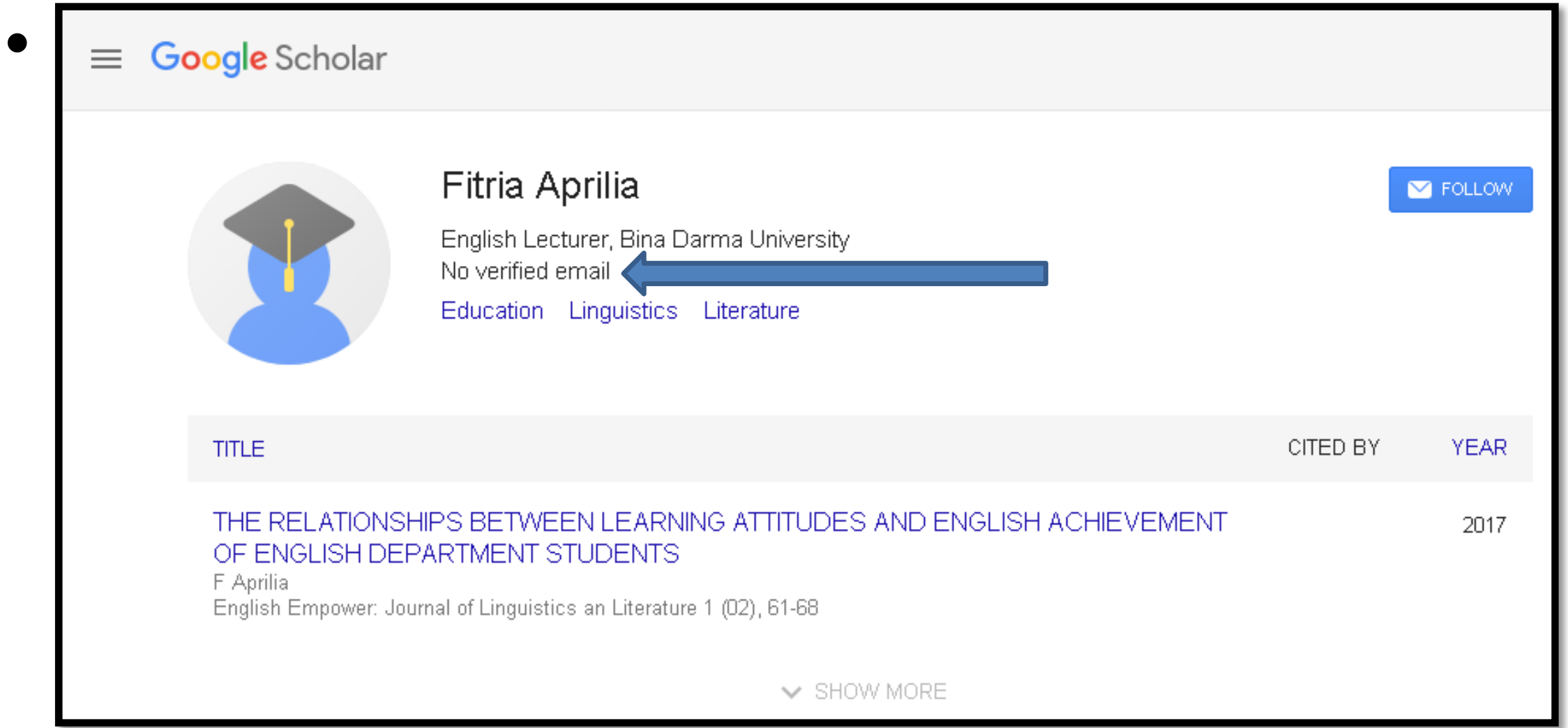




\section{Author Publication Journal URL}

- Journal URL $\rightarrow$ http://ejournal.unitaspalembang.ac.id/index.php/eejll/article/view/13

English Empower: Journal of Linguistics and Literature

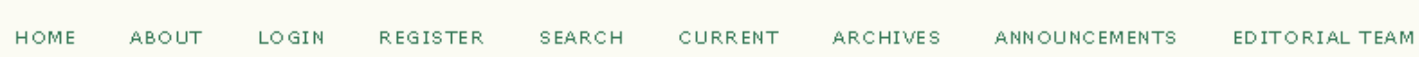

FOCUS AND SCOPE AUTHOR GUIDELINES

Home > Vol 1, No 02 (2016) > Aprilia

THE RELATIONSHIPS BETWEEN LEARNING ATTITUDES AND ENGLISH

ACHIEVEMENT OF ENGLISH DEPARTMENT STUDENTS

Fitria Aprilia

Abstract

Language learning attitudes (LLA) becomes one of the most crucial issues in educational field. The aim of this study is to investigate the

relationships between students' LLA and their English achievement (EA). To achieve the aim, the attitude questionnaire and the students' grade point average (GPA) of English subjects were administered to a group of 103 students of English Education Study Programs in Palembang. To analyze the data, Pearson product-moment correlation coefficient was used and the results showed significant correlations between students' (1) LLA(total) and their EA, and (2) positive attitude and their EA. Furthermore, regression analysis in the first and third university showed that students' LLA(total)

influences their EA for $8.9 \%$. Meanwhile, in the second university, students' positive attitude could influence their EA for $16.3 \%$. Finally, the

interpretation and implications of the results are also discussed.

Full Text:

PDF

\section{PDF Files}

References

Abidin, M. J. Z., Pour-Mohammadi, M., \& Alzwari, H. (2012). EFL students' attitudes towards learning English language: The case of Libyan secondary school students. Asian Social Science, 8(2), 119-134.

Ali, M., Kos, J., Lietz, P., Nugroho, D., Furqon., Zainul, A., \& Emilia, E. (2010). Measuring student learning achieve-ment in Madrasah. Jakarta: AusAiD and World Bank Indonesia. 


\section{Check Author Full Text [PDF]}

- $\quad$ Author Full Text (PDF) URL $\rightarrow$

http://ejournal.unitaspalembang.ac.id/index.php/eejll/article/view/13/13

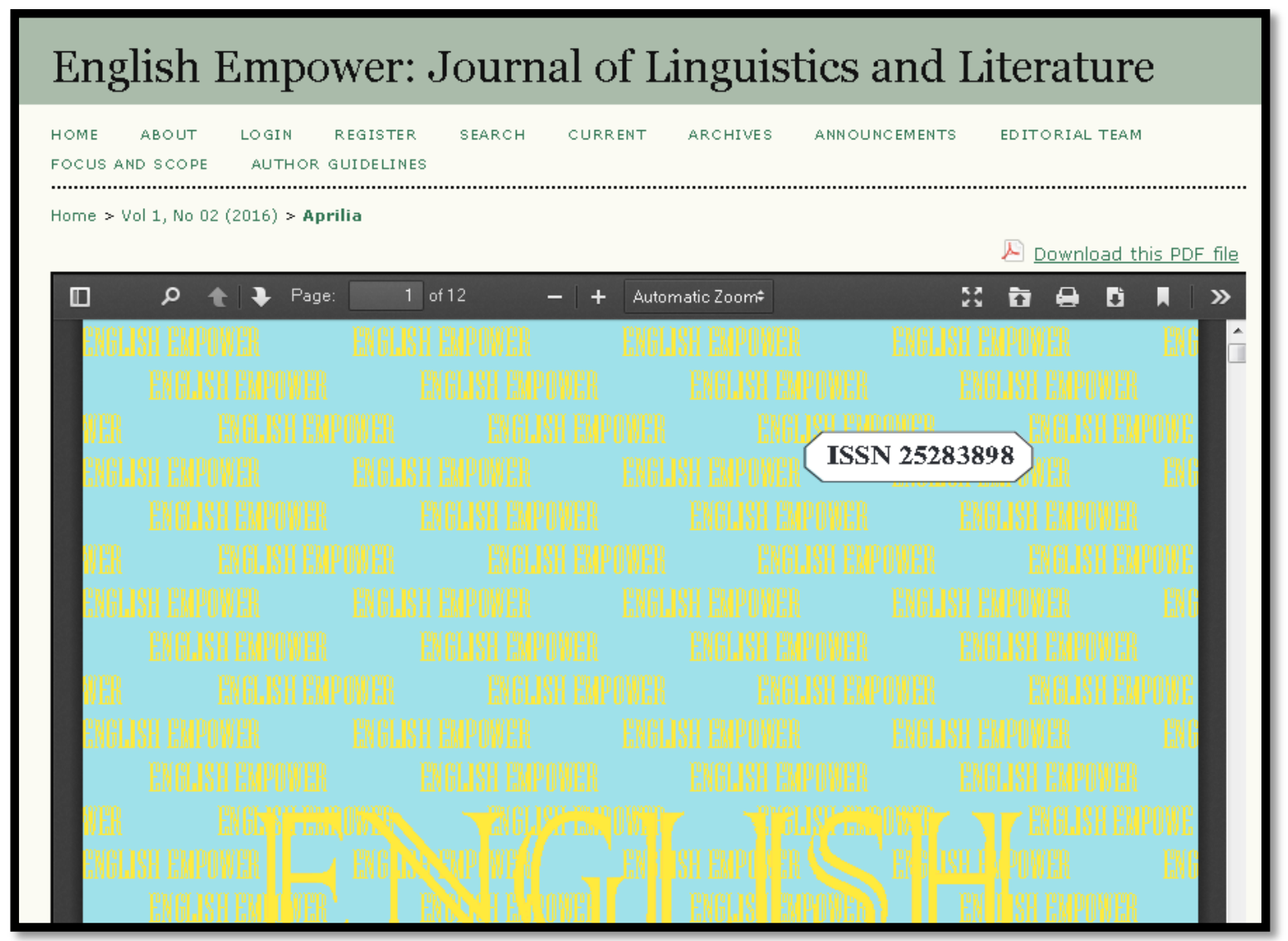




\section{Jumlah Artikel dalam Satu Edisi = 5}

- Terdiri atas minimal 5 articles dalam 1 edisi

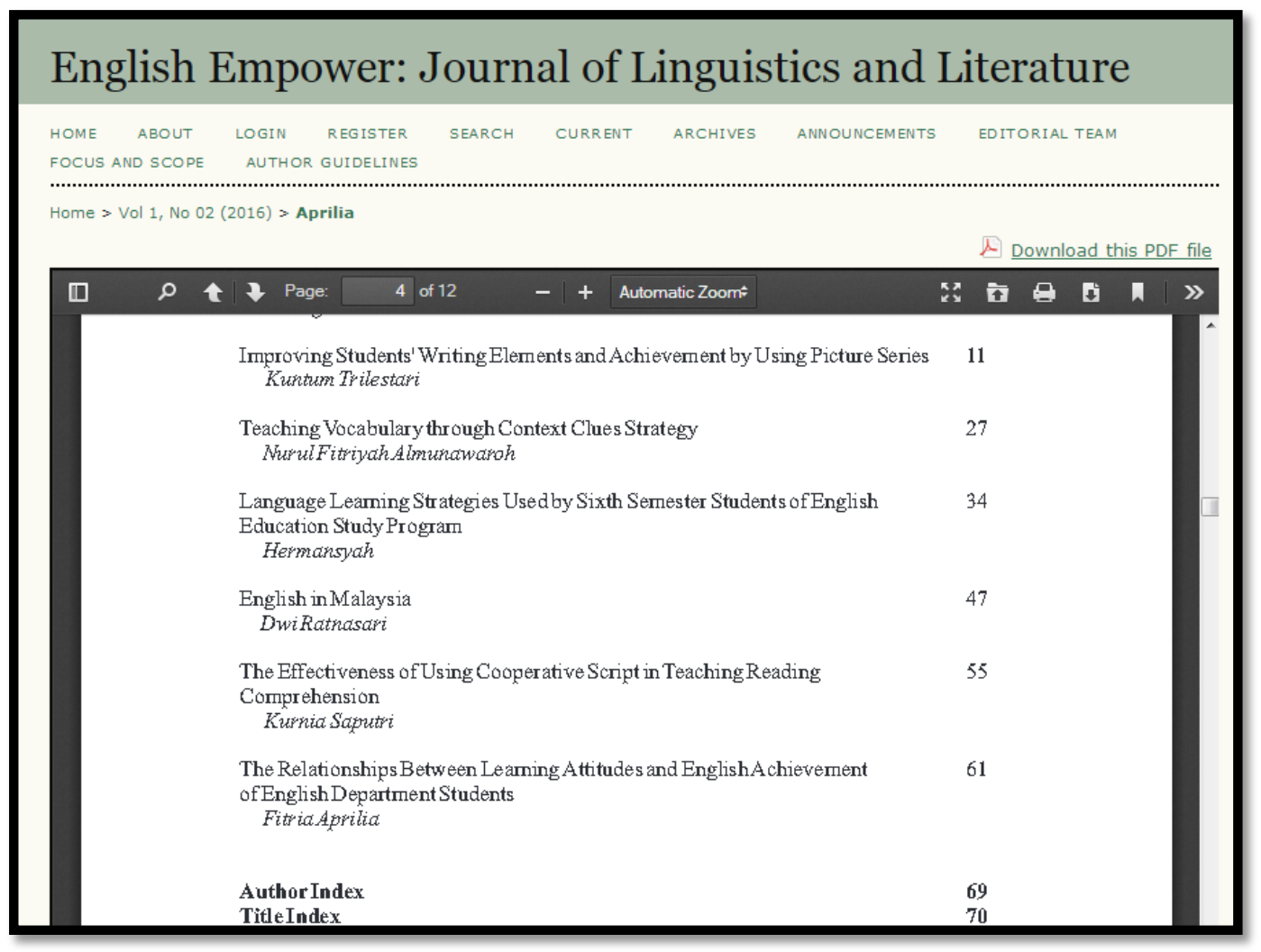




\section{Periksa Nama Author di Artikel}

- Author = "Fitria Aprilia"

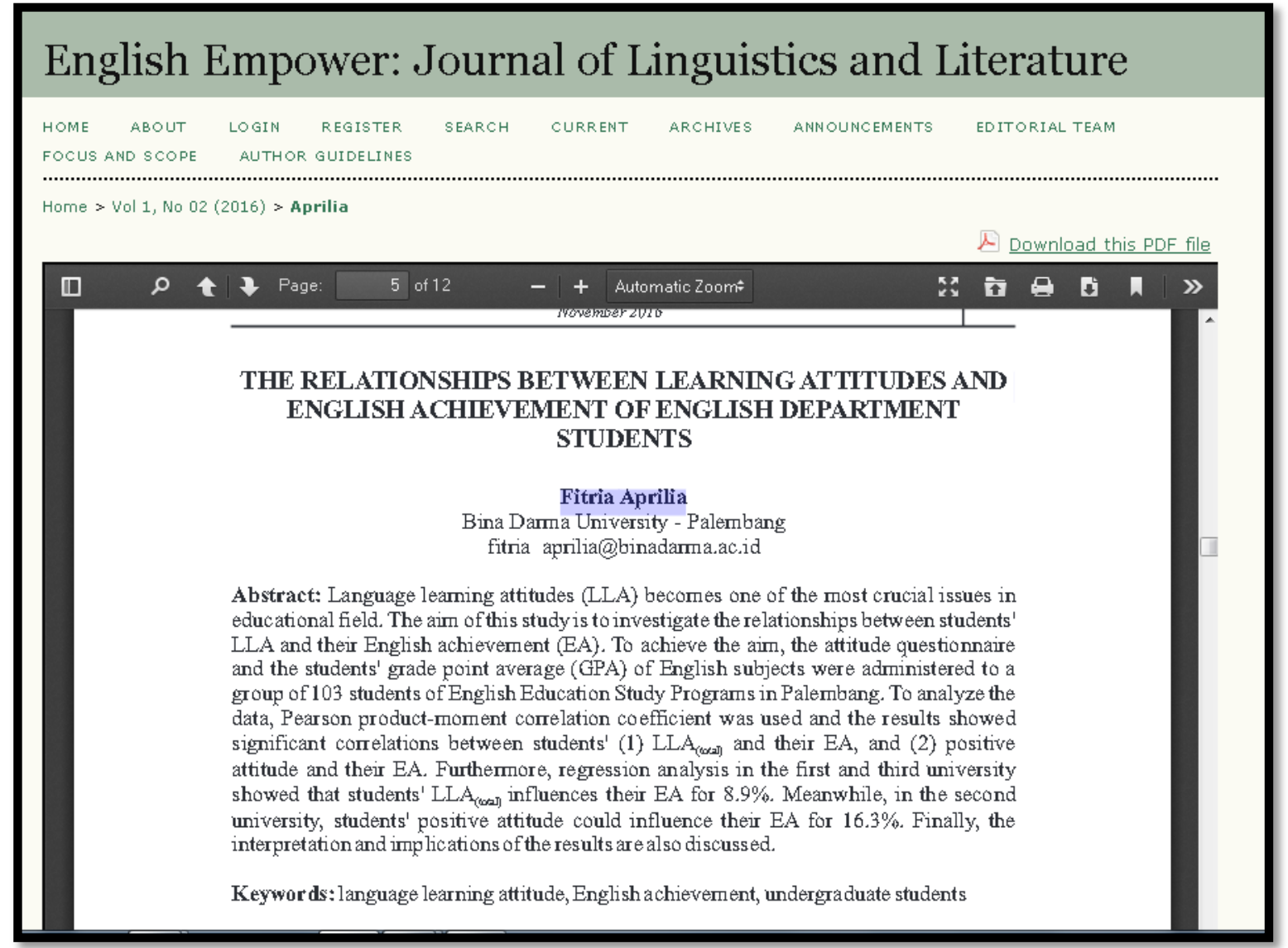


5. Verifikasi, Aktivasi \& Delete Akun Penulis

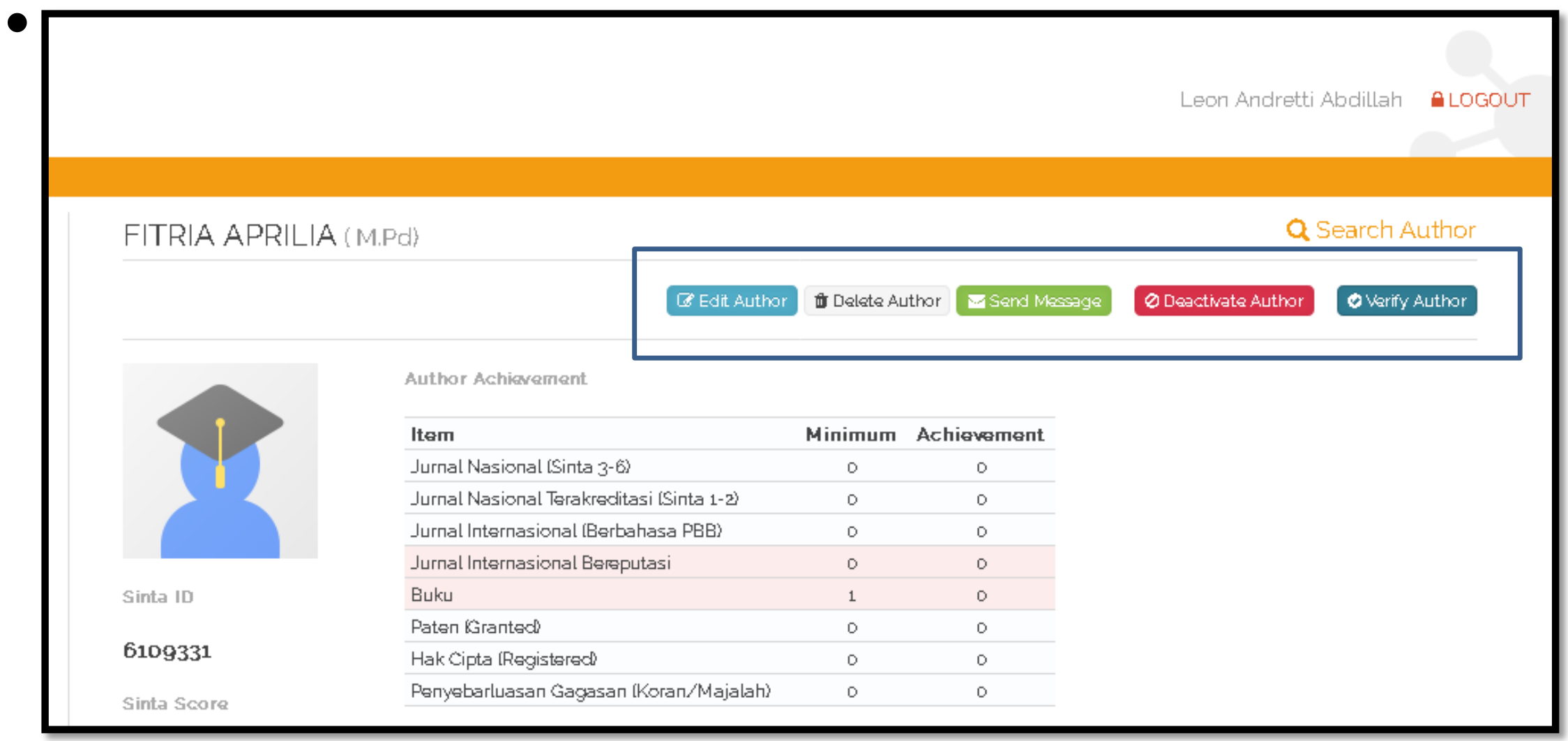




\section{Verified}

- Kalau semua Ok $\rightarrow$ verified

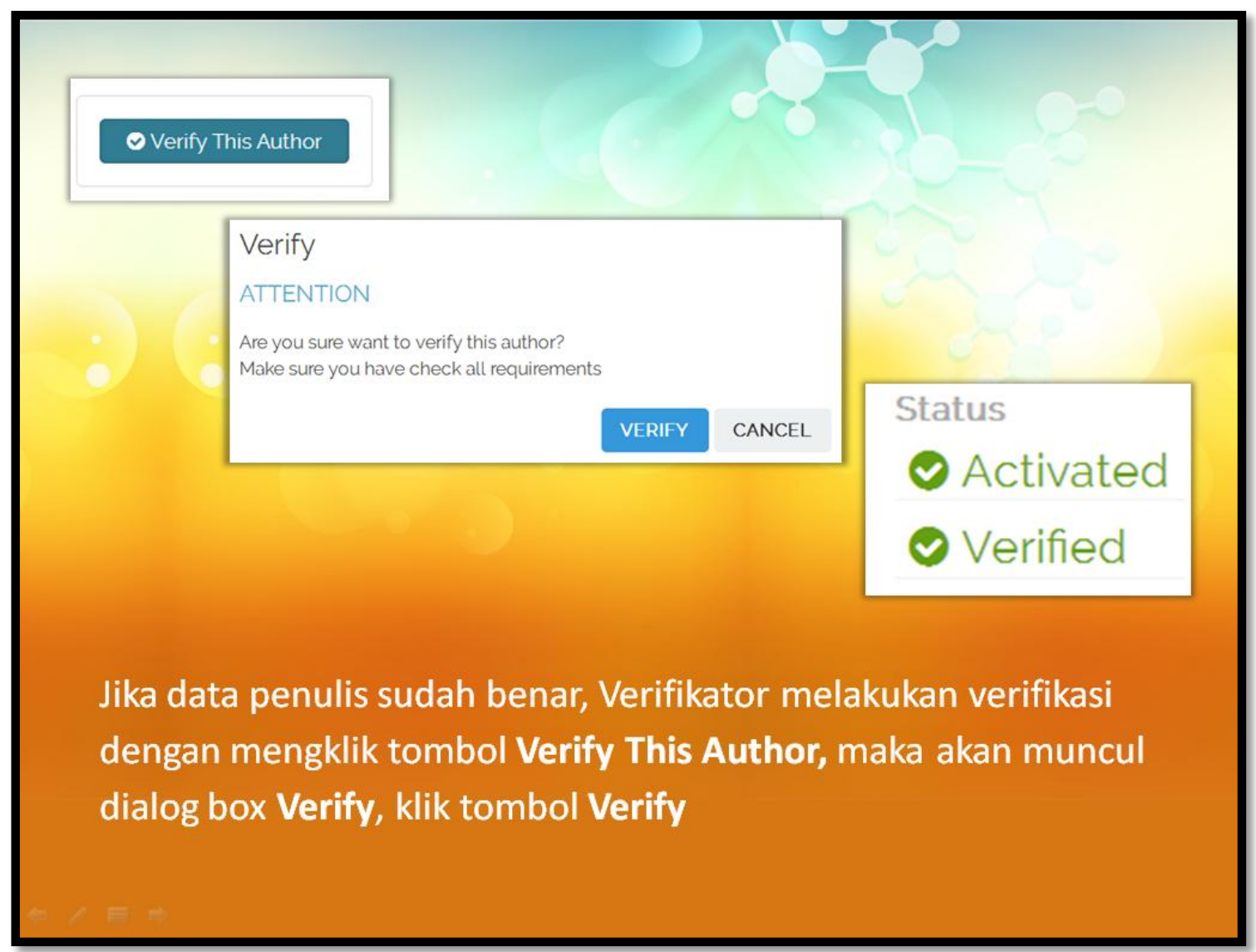




\section{SINTA Author Profile}

- Author Profile

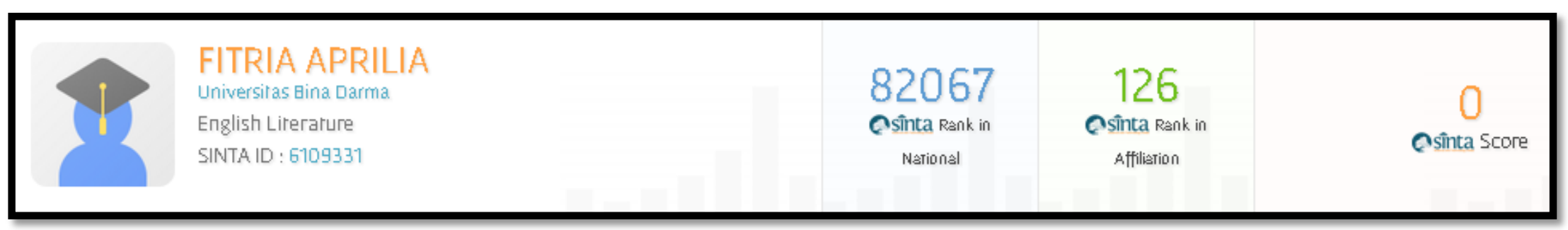




\section{Sinkronisasi SINTA}

- Misalnya : Muhamad Akbar

MUHAMAD AKBAR

NIDN: 0217027201 | Universitas Bina Darma | Fakultas ILmu Komputer (S1)

Email: muhamad.akbariobinadarma.ac.id | Academic Giade : seniorlecturer

- Author Profile in SINTA

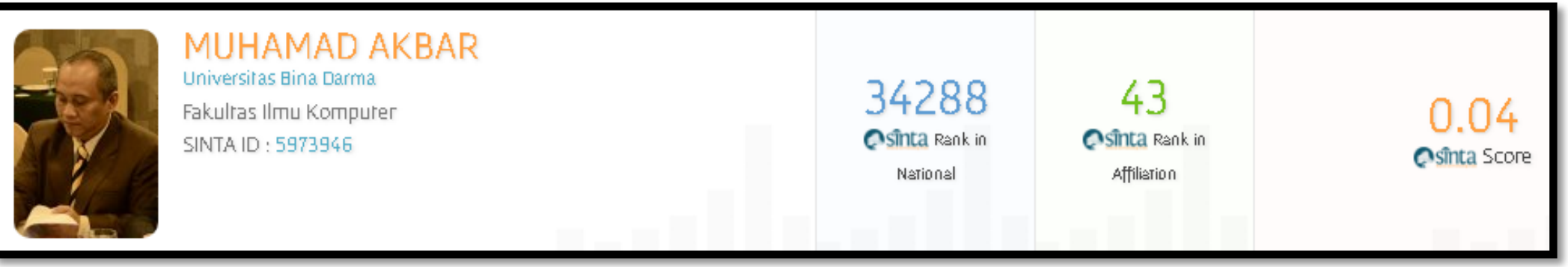




\section{Detail Author}

\begin{tabular}{|c|c|c|c|c|}
\hline & Author Achiavement & & & \\
\hline & Itam & Minimum & Achievament & \multirow{2}{*}{$\approx$ Request Google Sync } \\
\hline & Jurnal Nasional (Sinta 3-6) & o & D & \\
\hline & Jurnal Nasional Terakraditasi (Sinta 1-2) & o & D & \multirow{4}{*}{$\approx$ Request Scopus Sync } \\
\hline & Jurnal Internasional (Berbahasa PBB) & o & o & \\
\hline & Jurnal Internasional Begputasi & o & D & \\
\hline Sinta ID & Buku & 1 & o & \\
\hline \multirow{2}{*}{5973946} & Paten Granted) & o & o & \multirow[b]{3}{*}{ If Reset Google } \\
\hline & Hak Cipta (Registsred) & o & o & \\
\hline \multirow{4}{*}{$\begin{array}{l}\text { Sinta Score } \\
\mathrm{O} \\
\text { Status } \\
\text { Activated }\end{array}$} & Penyabarluasan Gagasan (Koran/Majalah) & o & o & \\
\hline & \multicolumn{3}{|l|}{$\begin{array}{l}\text { NIDN } \\
0217027201\end{array}$} & 向 Reset Scopus \\
\hline & \multirow{2}{*}{\multicolumn{3}{|c|}{$\begin{array}{l}\text { Academic Grade } \\
\text { Senior Lecturer (Lektor) }\end{array}$}} & \\
\hline & & & & \\
\hline$\bullet$ Verified & Afíliation & & & \\
\hline & & & & \\
\hline Verified By: & \multirow{2}{*}{\multicolumn{3}{|c|}{$\begin{array}{l}\text { Department } \\
\text { Fakultas Ilmu Komputer (S1) }\end{array}$}} & \\
\hline LIPI 7 & & & & \\
\hline & KKL62VKAAAAJ & & & \\
\hline & \multicolumn{3}{|l|}{ Scopus ID } & \\
\hline & chack [ & & & \\
\hline
\end{tabular}




\section{Sinkronisasi Google Scholar}

- Klik

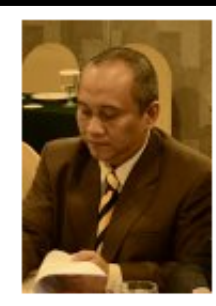

Sinta ID

5973946

Sinta Score

0.04

Status

- Activated

$\checkmark$ Verified

Verified By

LIPI 7

\section{Author Achiavement.}

Itam

Jurnal Nasional (Sinta 3-6)

Jurnal Nasional Terakreditasi (Sinta 1-z)

Jurnal Internasional (Berbahasa PBE)

Jurnal Internasional Berputasi

Buku

Paten Kranted

Hak Cipta IRøgistared

Panyabarluasan Gagasan (Koran/Majalah)

NIDN

0217027201

Acaderic Grade

Senior Lecturer (Lektor)

Afiliation

Universitas Bina Darma

Department

Fakultas Ilmu Komputer (S1)

Google Scholar ID

KKL62vKAAAAJ

chack $匚$

Scopus ID
Minimum Achiavement
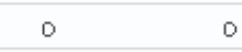

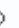

0

D

o
向 Reset Scopus

$\approx$ Request Scopus Syne

\section{而 Reset Google}




\section{Konfirmasi}

- Klik Yes

Google Sync

Are you sure want to request Google Scholar Documents Syncronization for this author?

- Loading

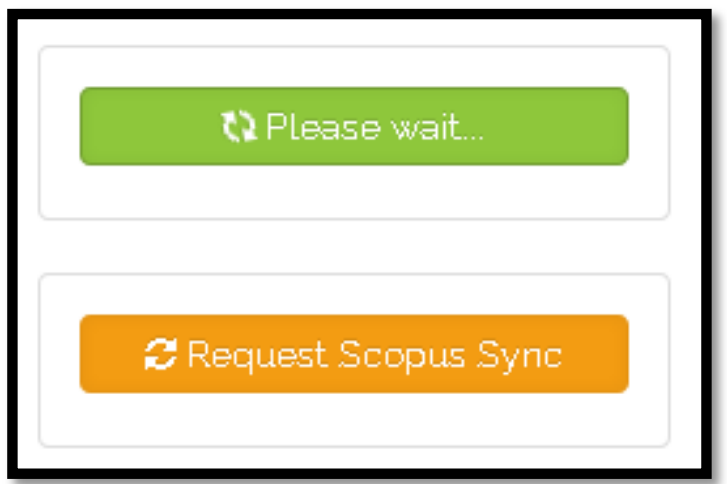




\section{Sinkron}

- Before

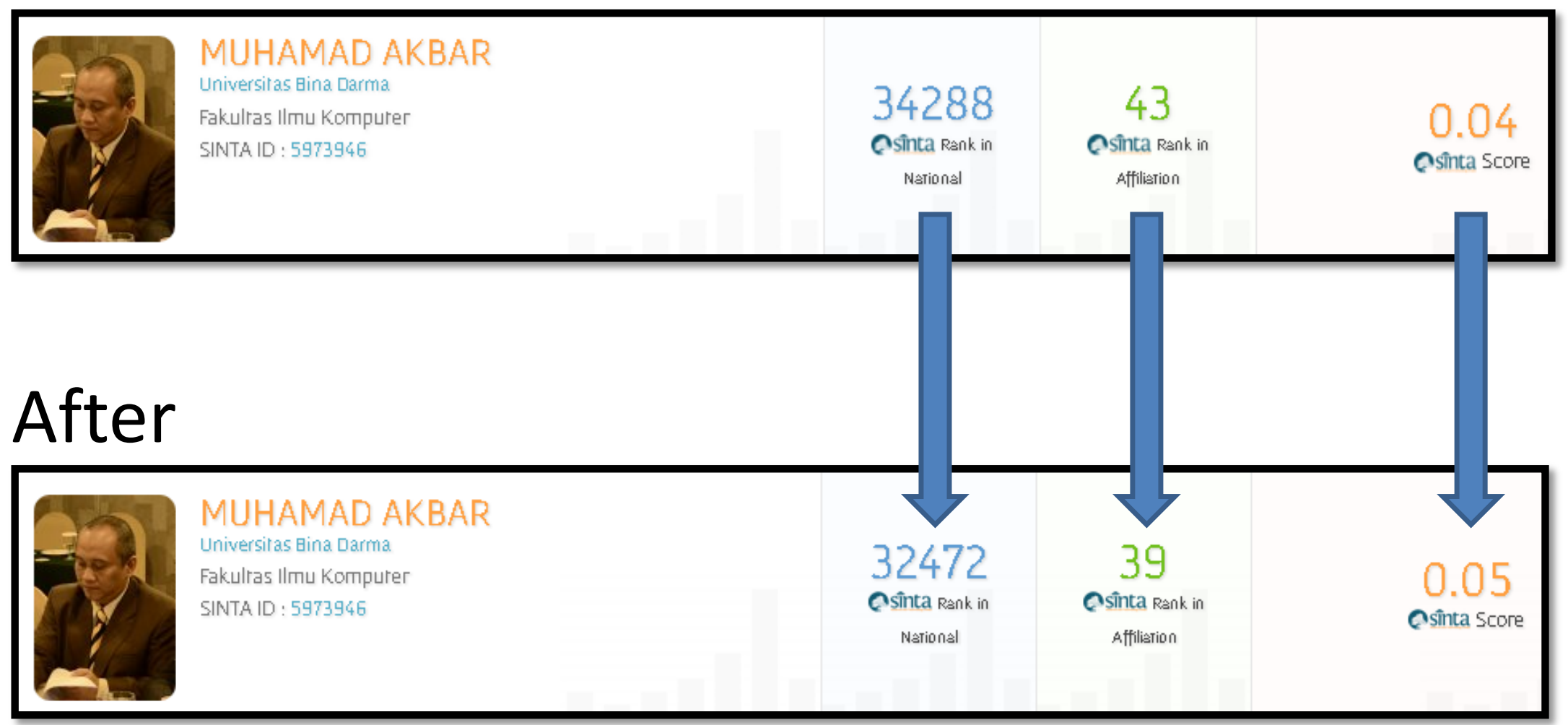




\section{Pendanaan Ristekdikti}

- Penggunaan SINTA sebagai media pengukur produktivitas riset dan pengabdian juga dioptimalkan dengan menggunakan Sinta ID dalam akses pendanaan melalui Simlitabmas (Ristekdikti, 2018) 


\section{Identitas Pengusul Hibah Ristekdikti}

\section{- Isian ID Sinta pada Usulan Hibah Ristekdikti}

\section{IDENTITAS}

a. Identitas Ketua Pengusul

1. NIDN/NIDK atau identitas resmi lainnya bagi non dosen

2. Nama peneliti

3. Pangkat dan Jabatan

4. Email pengusul

5. Isian curriculum vitae (CV) dengan menunjukkan riwayat data penelitian pengusul berupa isian data publikasi dan perolehan KI (judul, jenis dan status KI, serta dengan mencantumkan URL jika ada). Riwayat data peneliti berupa ID peneliti atau tautan/link/URL yang berisikan rekam jejak peneliti yang tercantum di lembaga pengindek nasional atau internasional secara daring (Sinta, Scopus, Thompson, Google Scholar, Microsoft Academic, dll.). Rekam jejak peneliti dapat juga ditunjukkan dalam bentuk daring lainnya, misalnya personal webpage.

6. Isian ID Sinta

7. Isian h-Index

8. Isian anggota peneliti Dosen/Non Dosen seperti isian 1-7 di atas 


\section{Profil SINTA Author UBD}

- Sampai dengan 2018-04-04

- Verified Authors $=126$

- Unverified Authors $=0$

SINTA University Verificator

Darma

Universitas Bina Darma

$\checkmark$ Update Affiliation

18. Dashboard

*ne Registered Authors

$\oslash$ Unverified Authors

O Edit Password

\section{Find Author}

NIDN Search

158

269

Sinta Rank

Registered Authors

Unverified Authors
O

Verified Authors

126
126 Activated Authors

O Not Activated Authors 


\section{Profil SINTA UBD}

- Sampai dengan 201-04-09

- UBD SINTA Rank = 158

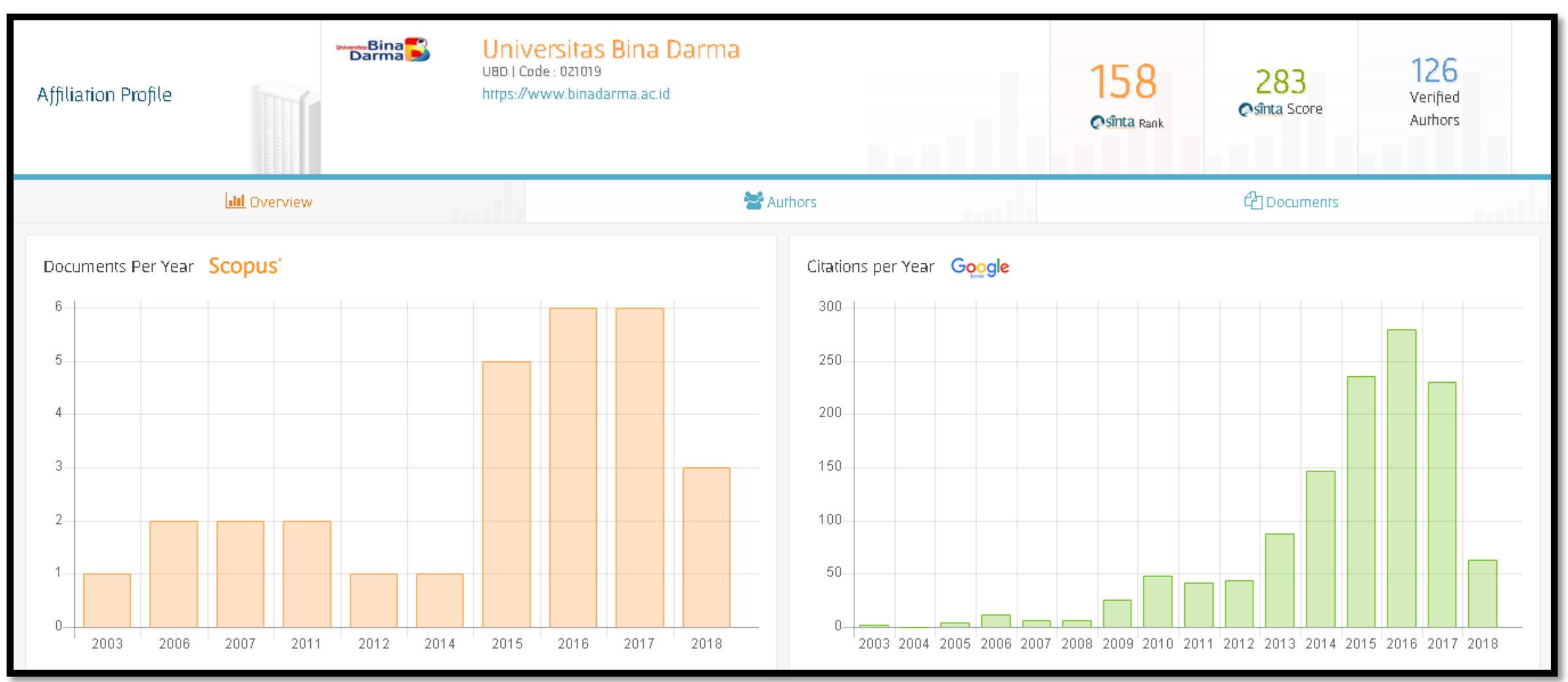




\section{Saran dan Harapan}

- Diharapkan semua dosen yang memiliki NIDN \& NIDK:

- Memiliki Account Google Scholar dengan data real

- Memiliki publikasi terindeks Scopus (diutamakan)

- Melakukan registrasi ke SINTA

- Kedepan siapkan account ORCID 


\section{References}

Abdillah, L. A. (2012). PDF articles metadata harvester. Jurnal Komputer dan Informatika (JKI), 10(1), 1-7.

Ristekdikti. (2018). Panduan Google Scholar. Jakarta: Direktorat Jenderal Penguatan Riset dan Pengembangan, Kementerian Riset, Teknologi, dan Pendidikan Tinggi.

Ristekdikti. (2018). Panduan Pelaksanaan Penelitian dan Pengabdian kepada

Masyarakat di Perguruan Tinggi Edisi XII Tahun 2018. Jakarta: Direktorat Riset dan Pengabdian kepada Masyarakat, Direktorat Jenderal Penguatan Riset dan Pengembangan Kementerian Riset, Teknologi, dan Pendidikan Tinggi.

Ristekdikti. (2018). Panduan Penulis Sinta. Jakarta: Direktorat Jenderal Penguatan

Riset dan Pengembangan, Kementerian Riset, Teknologi, dan Pendidikan Tinggi.

Ristekdikti. (2018). Panduan Verifikator Sinta. Jakarta: Direktorat Jenderal Penguatan Riset dan Pengembangan, Kementerian Riset, Teknologi, dan Pendidikan Tinggi. 


\section{Universitas Bina Darma}

9 April 2018, Palembang, INDONESIA
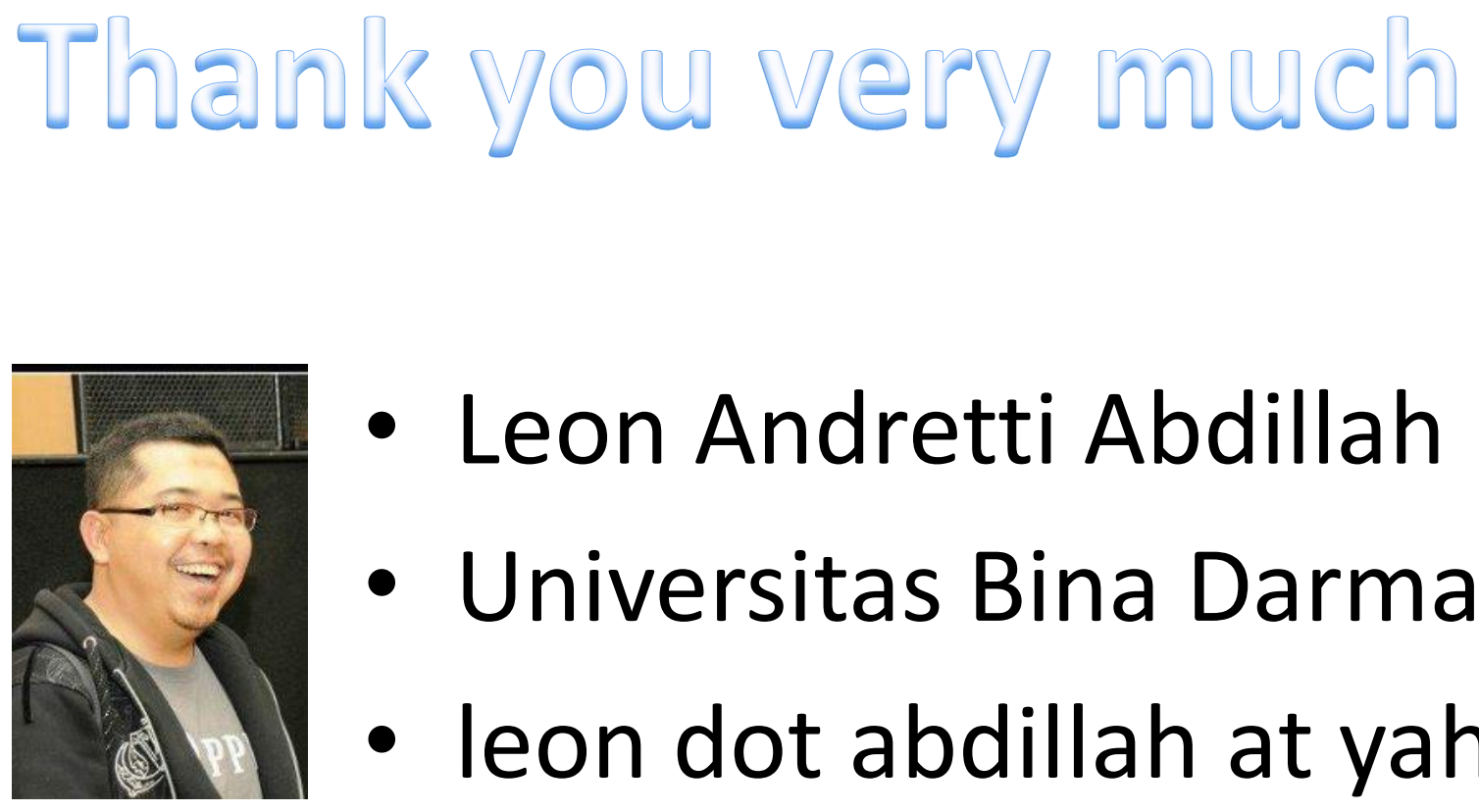

- Leon Andretti Abdillah

- Universitas Bina Darma

- leon dot abdillah at yahoo dot com

Abdillah, L. A. (2018). Science and Technology Index (SINTA) Verificator. Monday Weekly Briefing. Palembang: Universitas Bina Darma. 